\title{
Research on the Mechanism and Path of Social Work Intervening in Poverty Prevention Work — Taking Yanshan-Taihangshan Area as an Example
}

\author{
Jianying Kang ${ }^{1, *}$, Jiale Wang ${ }^{2}$, Xiangdong Xue ${ }^{3}$ \\ ${ }^{1}$ School of Public Administration, Hebei University of Economics and Business \\ ${ }^{2}$ School of Public Administration, Hebei University of Economics and Business \\ ${ }^{3}$ School of Public Administration, Hebei University of Economics and Business \\ *Jianying Kang (1972-), male, born in Dingzhou, Hebei province, doctor, professor. Email: kjy001@126.com
}

\begin{abstract}
After the completion of the targeted poverty alleviation strategy, my country has entered the stage of rural revitalization, but the fragile natural environment and economic and social environment of the Yanshan-Taihang Mountains still have some risks of returning to poverty, which restricts the development of the revitalization of new villages. Taking the Yan-tai Mountains area as an example, the article analyzes the implementation mechanism of social work intervention in poverty prevention work, and believes that the government's purchase of social work services can effectively integrate social resources, improve farmers' income and social governance performance, reduce poverty prevention costs, and promote the development of rural revitalization strategies.
\end{abstract}

Keywords: Social work, Anti-poverty mechanism, Rural revitalization

\section{INTRODUCTION}

2020 is the year when the goal of building a moderately prosperous society in all respects will be realized, and it will be the year when the fight against poverty is finally won in an all-round way. The YanshanTaihang Mountains area (referred to as Yantai area) has completed all 22 deeply impoverished counties under the influence of the implementation of the targeted poverty alleviation strategy, and the poverty alleviation work has done remarkable results. However, we must also be soberly aware that poverty is a worldwide problem, which is procedural and dynamic. The risk of returning to poverty still exists for some people who have escaped poverty under the fragile ecological and socio-economic environment of the Yantai area. According to statistics, the rate of returning to poverty in China's rural areas was basically above $20 \%$ from 2000 to 2015 . In $2009,62 \%$ of the poor were even returning to poverty [1]. Therefore, how to do a good job in poverty prevention after poverty alleviation is still not to be ignored, especially in the context of the implementation of the national village revitalization strategy, the small probability of returning to poverty is also one of the key points of government governance. So, how to prevent those who have been lifted out of poverty from returning to poverty?
According to the advanced experience of poverty prevention and treatment at home and abroad and the government's social governance theory, social work can play an active role in the governance and prevention of poverty. In terms of rate, social intervention can not only resolve the contradictions of the main body and coordinate the interests of all parties in a timely manner, but also reduce the cost of government governance. It also plays an important role in helping the needy and speeding up the process of poverty alleviation [2]. Antipoverty work in the context of rural revitalization requires the timely participation of social work.

\section{THE RESULTS OF POVERTY ALLEVIATION IN YANSHAN-TAIHANG SHAN AREA AND THE CAUSES OF POVERTY RETURN}

The Yantai area is located in the north and west of Hebei Province, with complex terrain, mainly plateaus and hills, harsh natural environment, frequent natural disasters, and backward economic development. The Yantai area includes 3 cities and 22 counties (formerly national-level extremely poor counties). Under the task of poverty alleviation, the region has actively cultivated 
characteristic industries, and the infrastructure and public services have been significantly improved. The problem of "two no worries and three guarantees" has been fully resolved, and the deep poverty fortress has been overcome as scheduled. While poverty reduction has achieved certain results, the anti-poverty mechanism has also been the first to be established. In 2019, Hebei Province first issued the "Opinions on Establishing and Improving a Long-term Mechanism for Poverty Alleviation and Prevention" to comprehensively and dynamically monitor marginalized groups returning to poverty. For various anti-poverty monitoring objects, various assistance measures such as industrial employment support, life guarantee for major diseases, civil affairs assistance, anti-poverty insurance, social assistance fund assistance, etc. will be taken in a targeted manner to achieve "zero return to poverty" for people out of poverty. Marginal groups "zero poverty".

Although the targeted poverty alleviation strategy is over and the poverty phenomenon in the Yantai area has been eradicated, but affected by factors such as resource endowments and location conditions, the overall development level of the Yantai area is relatively backward and the risk of returning to poverty is relatively high. There are three reasons: (1) Residents (The subject) have weak knowing and action ability, low stock of human capital and social capital, which limits the potential tapping, accelerates the intergenerational transmission of poverty, and lacks room for the development of the right to survival and development; (2) The level of social and economic endowment in Yantai area The infrastructure is relatively weak, and the absorption of labor and the improvement of social welfare are limited; (3) The natural ecological environment (carrier) in the Yantai area is poor, which is not conducive to the in-depth development of the agricultural industry.

\section{THE NECESSITY AND FEASIBILITY OF SOCIAL WORK INTERVENTION IN POVERTY PREVENTION WORK}

\subsection{The Need For Social Work To Intervene In Preventing Poverty Return}

As an important way of professional auxiliary administration, social work makes up for the shortcomings of a single administrative model, and has unique advantages in poverty prevention and poverty alleviation. Regardless of the value concept, the advantages of professional knowledge, or the loss of power of the targets of poverty alleviation, social work has strong pertinence, sustainability and feasibility for poverty prevention tasks.

First of all, from the point of view of value concept, social work follows the rights and potential of individual cases, and "people-oriented, helping others to help themselves" is its value pursuit. The values of social work are the basic premise of practical work and the inexhaustible driving force of the practical process. Although social work specializes in helping the poor, it does not produce "welfare dependence" on those who have been lifted out of poverty. Instead, they tap the potential and advantages of those who have been lifted out of poverty to improve their ability to provide life, improve their ability to know, do, and welfare, and prevent them. People who have been out of poverty have returned to poverty due to the sharp decline in income, achieving the goal of "teaching others to fish", thus realizing the value concept of "helping others to help themselves" [3]. Therefore, social work and government anti-poverty governance are the same in concept, especially in scattered, small, remote, and remote areas. The purchase of social work to serve poverty prevention will be more efficient, low-cost, and professional than the government's own governance.

Second, social work has unique professional advantages and can achieve government governance goals as soon as possible. The causes of poverty and return to poverty are nothing more than the individual case itself, socioeconomic resource endowments and natural environment carriers. For the governance social workers of the first two causes, they can use professional methods of individual case, group and community work to assess the possibility and vulnerability of return to poverty. According to the situation of different groups, different forecasting plans are adopted for the factors of returning to poverty of different groups, and professional technical interventions are given to scientifically intervene in the task of poverty prevention and governance. Therefore, social work will explore the potential of the client and the family from a professional perspective, integrate social resources (economic resources and institutional resources) to improve the knowledge and behavior of the case, thereby increasing income, preventing poverty, and alleviating the pressure on government departments.

Third, social work enhances the government's credibility by empowering clients, which is consistent with its goal of common prosperity. The target of returning to poverty is not only the income ability that cannot meet the needs of the family's survival and development, it is also a manifestation of the case's loss of power, and this is precisely the condition for social work to intervene and the field of professional expertise. The client's loss of power stems from his subjective feelings due to lack of ability or resources [4], his personal efficacy is low, lack of care, dependence, selfblame and helplessness and other negative emotions inhibit normal economic activities. And then unable to tap the potential of oneself, leading to return to poverty. The intervention of social work can not only improve the client's knowing and action ability, but also provide 
psychological counseling to people who have been lifted out of poverty in a unique way, focusing on emotional investment and increasing humanistic care.

\subsection{The Feasibility Of Social Work Intervention To Prevent Poverty Return}

Social work and targeted poverty alleviation have a certain compatibility in poverty alleviation concepts, poverty alleviation targets, and poverty alleviation goals, and their advantages have certain feasibility in antipoverty work.

First, social work has the function of linking resources. Social workers can widely identify various material and spiritual resources, are good at systematic resource analysis, combine formal resources and informal resources [5], contact relevant social organizations, and provide jobs for some people who are out of poverty. Economic strength, far away from the poverty line of returning to poverty.

Second, social work empowers people who have been lifted out of poverty. Most people who have been lifted out of poverty have not yet discovered their own advantages and potential, lack the necessary skills to earn a living, and are prone to return to poverty due to unexpected events. Social work uses case-by-case guidance, especially for rural young and middle-aged poor households, to help them improve their skills and accelerate social integration. In addition, through professional intervention and assistance, we will "delabel" people who get rid of poverty, eliminate inferiority and loss of power, enhance confidence and sense of selfachievement, promote the mental health of people who get rid of poverty, and actively respond to life difficulties.

Third, social work plays a role in supervision and evaluation of anti-poverty work. In the anti-poverty work in the deeply impoverished areas of Yantai area after being lifted out of poverty, social work has been effectively supervised to make up for the shortcomings of the government's single administration. Through monitoring the income data of poverty alleviation areas, assess the effect of poverty alleviation, and further carry out the implementation of corresponding anti-poverty work.

\section{THE PATH FOR SOCIAL WORK TO INTERVENE IN POVERTY PREVENTION}

Anti-poverty work is a key link in the task of poverty alleviation, and it is also the final sign of our victory in poverty alleviation. Before social work is involved in poverty prevention tasks, it is necessary to clarify the relationship between implementing agencies and personnel, target groups and the external environment, and make further planning and adjustments

\subsection{Establish Rural Social Institutions To Improve The Efficiency Of Executives}

Rural social work institutions provide a platform for social work to participate in poverty prevention in the Yantai area, and undertake specific matters of poverty prevention tasks. Rural social organizations must not only clarify their own responsibilities, improve the efficiency of executives, but also develop and strengthen the rural social work team.

First, establish rural social work service centers to coordinate and handle township and village affairs. The development of rural social work in Yantai area requires a platform and carrier to support the implementation of poverty prevention work. How to establish a rural social work service center? Considering the jurisdiction of townships and villages, it is possible to consider establishing a two-level linkage mechanism of stationcenter at the town and village levels, that is, to establish a large-scale social work service center at the township level, in administrative villages or natural villages. Establish a small-scale social work service station at the first level. Among them, the social work service center of the township is responsible for coordinating the work of this station, and is not responsible for specific matters, while the service station at the village level is responsible for the specific work within the village.

Second, develop rural social work teams and improve work efficiency. At present, rural social workers are relatively scarce, and social work is being invested in poverty prevention. We should vigorously develop rural social work teams. For graduates of social work majors in universities, encouragement measures and incentive policies are adopted to attract outstanding talents to social work. In addition, professional training is provided to social workers to enable them to understand the value concept of social work and master the methods of social work to improve work efficiency.

\subsection{Improve Communication Channels And Increase The Participation Of Target Groups}

The transformation of policy implementation into policy effects requires not only the effectiveness of the implementing agency, but also the approval and cooperation of the target group. Therefore, in order to achieve good policy results when social work is involved in poverty prevention tasks, it is necessary to improve communication channels and increase the participation of target groups. First, improve communication channels and listen to the voices of those who have escaped poverty. For those who have escaped the poverty line, they will always encounter problems that are difficult to participate in in their actual lives, and they should keep in touch with workers in a timely manner. On the one hand, social workers must make good use of the advantages of the village task force, strengthen the 
connection between the masses and cadres, and listen to the voices of those who are out of poverty; on the other hand, social work serves as a bridge for the people who are out of poverty to communicate with the government and society to safeguard the interests of the people. To monitor and evaluate the implementation of policies to avoid oppression of public opinion.

Second, stimulate endogenous development motivation and improve the ability of the poor to participate in society. First, construct an organizational guarantee for the value dimension. Social workers need to transmit to all members of the society the knowledge of a solid poverty alleviation and prevention of return to poverty, and be recognized by all members of the society, especially those who are alleviated from poverty, and form a good value orientation. Secondly, after actual inspections, social workers conduct anti-poverty work for those out of poverty based on the actual situation. At the same time, social workers strengthened positive operational reflexes. It means that people who get rid of poverty should combine their own experience, their own thinking, and their own conditions to spontaneously generate a desire not to return to poverty. Social workers play a helpful role in this process and really cultivate their livelihood ability.

Third, social workers assist families with labor to increase the stock of human capital. Social workers provide a re-learning and re-education platform for the monitored objects, and strive for opportunities for them to learn new knowledge and new skills. Encourage the poor to self-learn, self-improve, master certain market knowledge, and actively participate in market activities. At the same time, help the children of poor families receive higher education, provide material and spiritual support, and prevent the phenomenon of intergenerational transmission of poverty.

\subsection{Pay Attention To The Transformation Of The Macro-Environment And Vigorously Promote The Construction Of The Cultural Environment}

Weak infrastructure, traffic congestion, and backward information are one of the important factors that lead to poverty in the Yantai area. These factors are also likely to lead to the return of the vulnerability of poor areas to poverty. While social work pays attention to the construction of a macro environment, it must also vigorously promote cultural and educational services to provide a good environment for policy implementation, so as to solve the basic problems of the long-term development of the Yantai area.

First of all, social work is involved in the poverty prevention task in the Yantai area. It not only pays attention to the micro-environment of poverty-stricken families, but also pays attention to mobilizing poverty alleviation objects to actively create the macroenvironment. Social workers use the workforce of poverty alleviation targets to improve infrastructure construction, involve the masses in the construction, and provide procedural guidance and training. On the one hand, workers have the skills to earn a living and generate proactive enthusiasm, so as to solve employment problems and achieve the goal of poverty prevention; in addition, in the process of infrastructure creation, they can better find problems, save costs, and stabilize poverty alleviation effects. Social workers can brainstorm ideas and make suggestions for the government. Through vigorous publicity and fund-raising, provide guarantee for the creation of infrastructure.

Second, organize excellent cultural activities to speed up the social integration of poverty alleviation targets. The low level of cultural education, lack of knowledge and other important reasons restrict the development of those who have escaped from poverty. For poor households who have been below the poverty line for a long time, they will feel inferiority due to psychological pressure. Social workers organize excellent cultural activities based on the actual conditions of those who have been lifted out of poverty, relying on the local culture that they love to hear and see, to expand the circle of contacts among those who are lifted out of poverty, and to encourage them to integrate into society. By creating a positive cultural atmosphere, spreading correct values, and passing on cutting-edge knowledge and skills to those who are out of poverty, not only can they enrich their spiritual life, but they can also mobilize their own enthusiasm for poverty prevention tasks.

\section{CONCLUSIONS}

The implementation of the targeted poverty alleviation policy has eliminated absolute poverty, but relative poverty and occasional poverty will still exist. Taking the Yanshan-Taihangshan area as an example, this paper analyzes the main role, implementation mechanism and feasibility of social work in poverty prevention work, and believes that social work intervention in poverty prevention can help integrate resources, empower power, and government supervision and evaluation. The government's purchase of social work services can effectively broaden the channels for mass participation, reduce the cost of poverty prevention, facilitate the efficient implementation of poverty return work, and improve the performance of social governance. To this end, actively establish rural social institutions, encourage participatory development, and improve the macro environment to lay the foundation for the intervention of poverty prevention in social work.

\section{ACKNOWLEDGMENTS}

This study is supported by the Hebei Social Science Fund Project: Research on social work intervention 
mechanism of targeted poverty alleviation in Yanshan Taihang poverty belt (HB19SH014).

\section{REFERENCES}

[1] Zheng Ruiqiang, Cao Guoqing. The poverty alleviation population returns to poverty: influencing factors, mechanism of action and risk control[J]. Journal of Jiangxi Agricultural University (Social Science Edition), 2016, 015(006):619-624.

[2] Gao Fei. New poverty governance in the post-poverty era: the positioning and role of social work - a long-term comparative perspective $[\mathrm{J}]$. Inner Mongolia Social Sciences, 2020(6): 156-163

[3] Fan Jiaxu. Social work intervention in rural poverty alleviation from the perspective of advantage: fit and path selection[J]. World of Labor and Social Security, 2017(12): 15-16

[4] Cai Yanxun. Research on social work intervention in precision poverty alleviation from the perspective of empowerment theory[J]. Entrepreneur of the South, 2018, 01:116-116

[5] Wang Sibin. Social work participation in targeted poverty alleviation_-Also on practical targeted poverty alleviation[J]. Social Work, 2016(3):3 